\title{
Effect of prop-1-ene-1,3-sultone on the Performances of Lithium Cobalt Oxide/Graphite Battery Operating Over a Wide Temperature Range
}

\author{
Wenfeng Song ${ }^{1,2}$, Bo Hong ${ }^{1, *}$, Shu Hong ${ }^{1, *}$ Yanqing Lai ${ }^{2}$, Jie Li $^{2}$, Yexiang Liu ${ }^{2}$ \\ ${ }^{1}$ School of Materials Science and Engineering, Central South University, Changsha, Hunan 410083, \\ China \\ ${ }^{2}$ School of Metallurgy and Environment, Central South University, Changsha Hunan 410083, China; \\ *E-mail: miaoshoushu1234@163.com and bop_hong@163.com
}

doi: $10.20964 / 2017.11 .84$

Received: 30 July 2017 / Accepted: 19 September 2017 / Published: 12 October 2017

In this paper, we find that prop-1-ene-1,3-sultone (PES) must be a promising additive for the lithium ion battery operating over a wide temperature range. The effect of PES on the graphite anode and $\mathrm{LiCoO}_{2}$ cathode is systematically studied by cyclic voltammetry (CV), charge-discharge test, scanning electron microscopy (SEM), and X-ray photoelectron spectroscopy (XPS). The results demonstrate that PES could be reduced prior to the ethylene carbonate (EC) and formed a more stable SEI film on the graphite anode. Meanwhile, the PES could also form a film on $\mathrm{LiCoO}_{2}$ electrode. For these reasons, the $\mathrm{LiCoO}_{2} /$ artificial graphite (AG) battery using PES additive exhibits an excellent high temperature performances. The battery with PES additive could bear $2 \mathrm{C}$ charge/discharge cycle under $70^{\circ} \mathrm{C}$ and the capacity retention could reach $90.1 \%$ after 300 cycles. Although PES additive will little increase the resistance of $\mathrm{LiCoO}_{2} / \mathrm{AG}$ cells and harm its low temperature performance, the discharge capacity retention of the battery with $1 \%$ PES can still reach $75 \%$ at $-40^{\circ} \mathrm{C}$. This demonstrates that PES must be a very promising additive for the battery operating over a wide temperature range.

Keywords: Lithium-ion battery, Electrolyte additive, Prop-1-ene-1,3-sultone, low temperature performance, high temperature performance, wide temperature range

\section{FULL TEXT}

(C) 2017 The Authors. Published by ESG (www.electrochemsci.org). This article is an open access article distributed under the terms and conditions of the Creative Commons Attribution license (http://creativecommons.org/licenses/by/4.0/). 